\title{
Fault extent of the largest aftershock of the 1968 Tokachi-Oki, Japan, earthquake and an interpretation of the normal faulting focal mechanism
}

\author{
Yasuo Izutani \\ Shinshu University, 4-17-1 Wakasato, Nagano, Japan \\ (Received February 18, 2011; Revised July 27, 2011; Accepted July 28, 2011; Online published February 21, 2012)
}

\begin{abstract}
The focal mechanism of the 1968 Tokachi-Oki earthquake $\left(M_{\mathrm{J}}=7.9\right)$ was thrust faulting but that of the largest aftershock $\left(M_{\mathrm{J}}=7.5\right)$ was normal faulting. The tectonic implication of the reversal of the focal mechanisms of the two events has not been clarified yet. In order to investigate this, we ought to take into account the relative location of the two fault planes. In the present study, the length and the direction of rupture propagation for the largest aftershock is derived from the azimuth dependence of the duration of observed strong ground motion. If we assume that the rupture initiation point is the hypocenter location determined by the Japan Meteorological Agency (JMA), the location of the fault plane is considerably further north of the tsunami source area as estimated previously, and at the northern end of the aftershock area within 24 hours after the main shock. The fault plane of the largest aftershock is deeper than that of the main shock and the two fault planes are nearly parallel to each other. The thrust faulting of the main shock and the normal faulting of the largest aftershock indicate that the part of the Pacific plate between the two fault planes moved relatively further northwestward due to the two events than the deeper part beneath the fault plane of the largest aftershock.
\end{abstract}

Key words: 1968 Tokachi-Oki earthquake, largest aftershock, fault extent, normal faulting, reversal of focal mechanisms.

\section{Introduction}

Aftershocks are considered to be triggered by a static and/or dynamic stress disturbance due to the main shock (e.g., King et al., 1994; Felzer and Brodsky, 2006), and in most cases, the focal mechanisms of aftershocks are similar to that of the main shock. It is, therefore, quite unusual that the focal mechanism of the 1968 Tokachi-Oki earthquake $\left(M_{\mathrm{J}}=7.9\right)$ is thrust faulting but that of the largest aftershock $\left(M_{\mathrm{J}}=7.5\right)$, which occurred about 10 hours after the main shock, is normal faulting, as shown in Fig. 1 and Table 1.

The thrust faulting for the main shock is due to the descending motion of the Pacific plate beneath the Japan arc (Kanamori, 1971). The direction of motion of the foot-wall side during the main shock is $300^{\circ}$ in azimuth. It is almost equal to $301^{\circ}$ for the 2003 Tokachi-Oki earthquake $\left(M_{\mathrm{J}}=8.0\right)$ and indicates the direction of motion of the Pacific plate against the Japan arc. On the other hand, the direction of motion of the foot-wall side during the largest aftershock is $144^{\circ}$, which is nearly opposite to the direction of motion of the Pacific plate. Kanamori (1971) attempted to explain this unusual reversal of focal mechanisms of the two large events by assuming a very complex interaction between the plates near the junction of the Japan and the Kuril trenches. Meanwhile, Yamakawa et al. (1972) presented

Copyright (C) The Society of Geomagnetism and Earth, Planetary and Space Sciences (SGEPSS); The Seismological Society of Japan; The Volcanological Society of Japan; The Geodetic Society of Japan; The Japanese Society for Planetary Sciences; TERRAPUB. an interpretation of the normal faulting focal mechanism of the largest aftershock by considering the static stress change caused by the main shock. Although the reversal of focal mechanisms would provide important information for understanding the plate movement near the junction of the Japan and the Kuril trenches, it has not been clarified yet.

In order to reveal the tectonic implication of the reversal of focal mechanisms, not only the hypocenter locations and the focal mechanism solutions of the two events, but also the relative location of the two fault planes ought to be taken into account. The spatial distribution of aftershocks within 24 hours after the main shock, shown in Fig. 1, suggests that the length of the fault plane of the main shock was about $150 \mathrm{~km}$ along the fault strike and the width was about $100 \mathrm{~km}$ along the dip direction (Kanamori, 1971). On the other hand, the fault plane of the largest aftershock is not known, because the largest aftershock occurred only 10 hours after the main shock, and the aftershock distribution cannot be used to estimate the fault plane of the largest aftershock. Although Hatori (1969) estimated the tsunami source area of the largest aftershock, it is desirable to infer the fault plane from seismic data. In the present study, we attempt to infer the fault plane of the largest aftershock from records of strong ground motion. We apply the method presented by Izutani and Hirasawa (1987a, b) for evaluating the fault length and the direction of rupture propagation from the azimuth dependence of the duration of strong ground motion. 
Table 1. 1968 Tokachi-Oki earthquake and its largest aftershock.

\begin{tabular}{|c|c|c|c|c|c|c|c|c|c|}
\hline Event & $\begin{array}{c}\text { Date } \\
(\mathrm{y} \mathrm{m} \mathrm{d} \mathrm{h} \mathrm{m)})\end{array}$ & $\begin{array}{l}\text { Latitude } \\
(\mathrm{N})\end{array}$ & $\begin{array}{l}\text { Longitude } \\
\text { (E) }\end{array}$ & $\begin{array}{c}\text { Depth } \\
(\mathrm{km})\end{array}$ & $M_{\mathrm{J}}$ & $\begin{array}{l}\mathrm{DD}_{1} \\
(\mathrm{deg})\end{array}$ & $\begin{array}{l}\mathrm{DA}_{1} \\
(\mathrm{deg})\end{array}$ & $\begin{array}{l}\mathrm{DD}_{2} \\
(\mathrm{deg})\end{array}$ & $\begin{array}{l}\mathrm{DA}_{2} \\
(\mathrm{deg})\end{array}$ \\
\hline Main shock & 196805160948 & 40.73 & 143.58 & 0 & 7.9 & -114 & 20 & 120 & 78 \\
\hline Largest aftershock & 196805161939 & 41.42 & 142.85 & 40 & 7.5 & -69 & 11 & 144 & 81 \\
\hline
\end{tabular}

Date (Japan Standard Time. GMT $+9 \mathrm{~h}$ ) and hypocenter location: after Japan Meteorological Agency (JMA). $M_{\mathrm{J}}$ : JMA magnitude. DD 1 , DA 1 , DD 2 , $\mathrm{DA}_{2}$ : dip direction and dip angle of two $P$-wave nodal planes after Kanamori (1971).

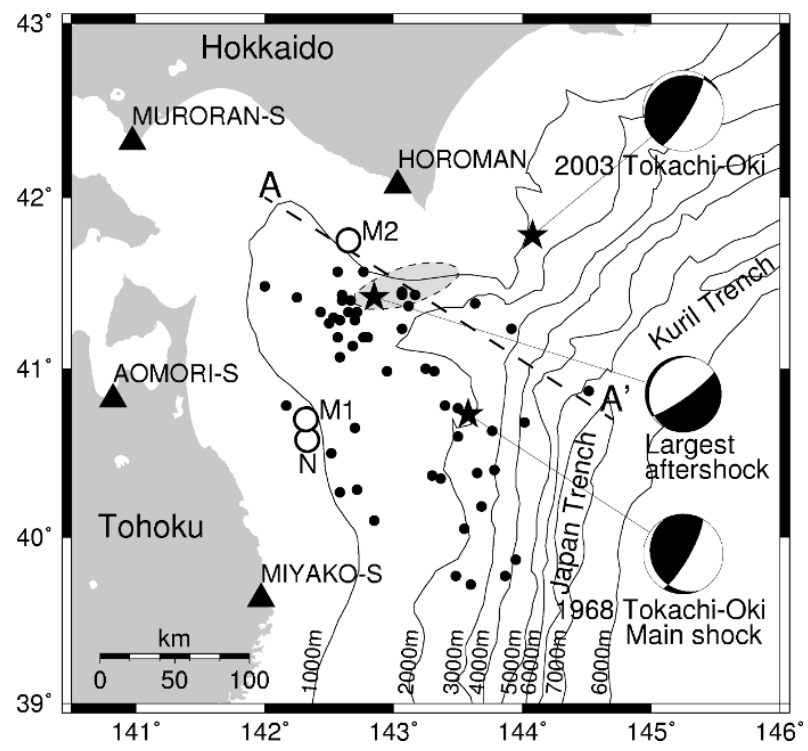

Fig. 1. Epicenters (solid stars) and focal mechanism solutions of the 1968 Tokachi-Oki earthquake, its largest aftershock, and the 2003 Tokachi-Oki earthquake. The solid triangles indicate strong motion observation stations. The sold circles show epicenters of aftershocks within 24 hours after the 1968 Tokachi-Oki earthquake. The open circle with ' $\mathrm{N}$ ' indicates the epicenter of I-phase determined by Nagamune (1971), and those with 'M1' and 'M2' are the locations of subevents by Mori and Shimazaki (1984). The thick broken line marked with A and $\mathrm{A}^{\prime}$ is approximately parallel to the direction of motion of the Pacific plate. The shaded ellipse indicated by a broken line indicates the fault plane of the largest aftershock derived in the present study.

\section{Data and Method}

Figure 2 shows horizontal component accelerograms recorded at the four observation stations shown in Fig. 1 (Tsuchida et al., 1969; Report no. SE-29 of the World Data Center A for Solid Earth Geophysics). Accelerograms were recorded at seven observation stations during the main shock, but unfortunately, at only the four observation stations during the largest aftershock. Since the accelerographs were triggered by ground motions above a certain preset amplitude level, ground motions with a smaller amplitude, such as the initial part of $P$-waves and the later part of coda waves, were not recorded.

Following Izutani and Hirasawa (1987a, b), we obtain the duration of strong ground motion. First, the accelerograms are filtered by a band-pass filter between 5 and $10 \mathrm{~Hz}$ in order to remove the effect of surface waves. Then, the cumulative power,

$P(t)=\int_{0}^{t}\left\{H_{1}(t)^{2}+H_{2}(t)^{2}\right\} d t / \int_{0}^{T}\left\{H_{1}(t)^{2}+H_{2}(t)^{2}\right\} d t$,

is calculated from two horizontal component band-pass fil-

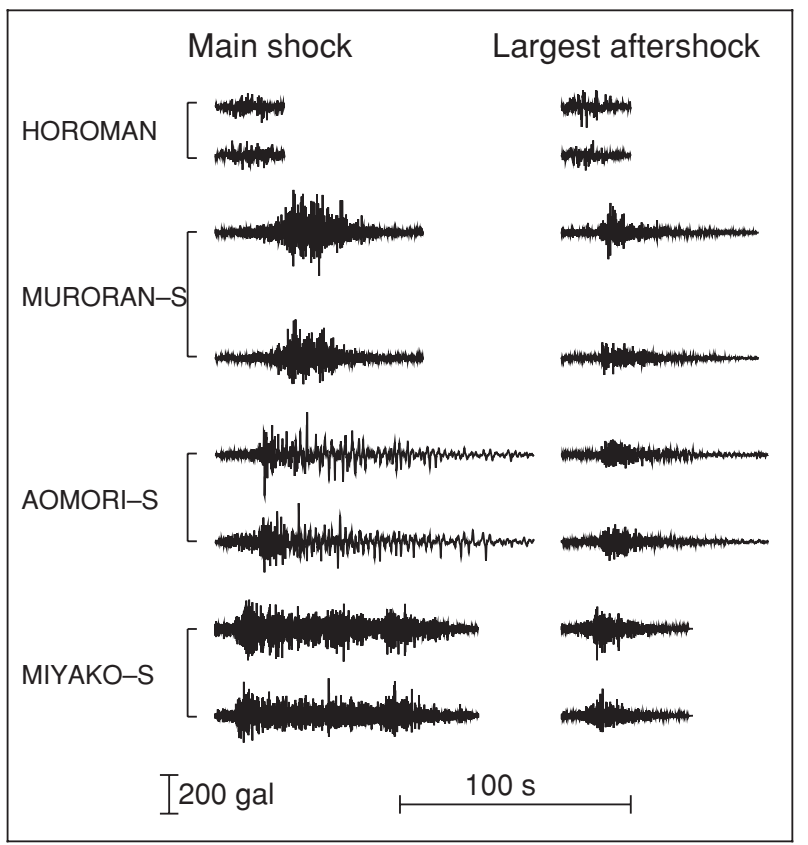

Fig. 2. Horizontal component accelerograms for the main shock and the largest aftershock at the four observation stations.

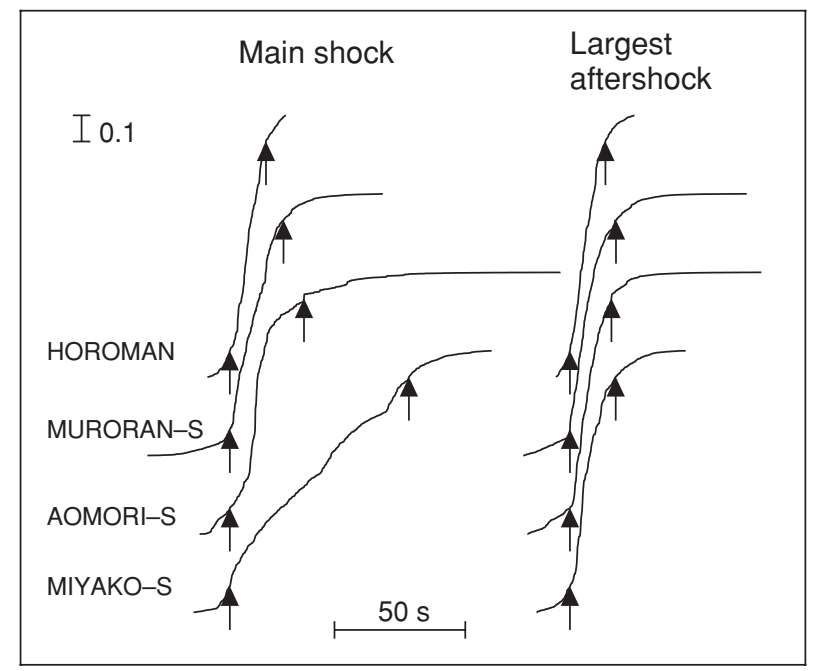

Fig. 3. Cumulative power curves of 5 to $10 \mathrm{~Hz}$ band-pass filtered accelerograms. The arrows show the time when the cumulative power is 0.1 and/or 0.9. Strong motion duration is defined as the time interval for the cumulative power to increase from 0.1 to 0.9 .

tered accelerograms, $H_{1}(t)$ and $H_{2}(t) . T$ is the total duration of the accelerograms. Figure 3 shows the cumulativepower curves for the accelerograms in Fig. 2. The strong motion duration, $D_{i j}$, is obtained objectively as the time in- 

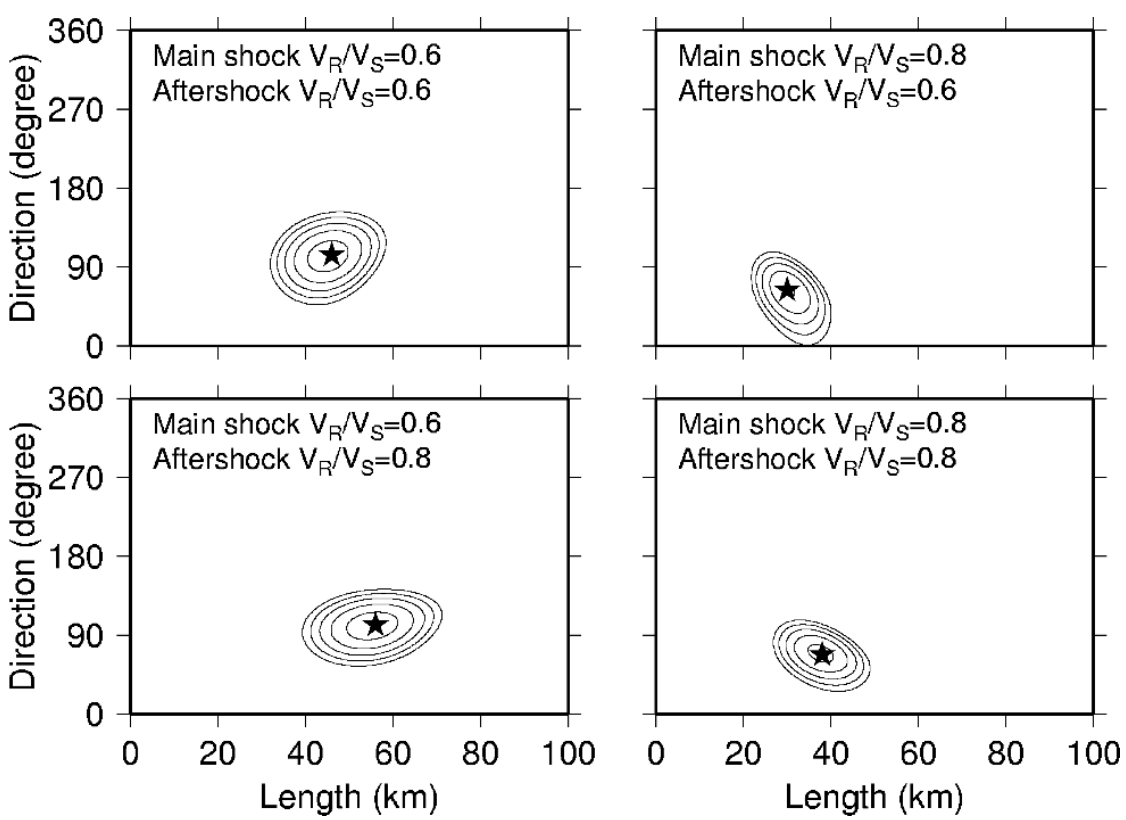

Fig. 4. Sum of the squares of residuals, $\epsilon^{2}$, between observed strong motion durations and calculated ones. The outermost contour in each figure indicates $\epsilon^{2}=100 s^{2}$, and the contour interval is $20 s^{2}$. The stars indicate the points where $\epsilon^{2}$ is the minimum.

terval between $P(t)=0.1$ and $P(t)=0.9$, where $i$ and $j$ stand for the earthquakes and the observation stations. Izutani and Hirasawa (1987a, b) have shown that the thus defined strong motion duration, $D_{i j}$, has no clear dependence on the source-to-site distance and is not significantly affected by the absence of the initial part of $P$-waves and the later part of coda waves. Also they have pointed out that $D_{i j}$ has a strong correlation with the duration time of rupture propagation on the fault plane.

We deal with only unilateral and/or symmetric bilateral rupture propagation, because the number of observed records is insufficient to evaluate parameters representing general cases of rupture propagation. For asymmetric bilateral rupture propagation, the result for the unilateral case might show the principal side of the fault plane.

When a rupture propagates on the fault plane of event $i$, the time interval between the first and the last arrivals of $S$-waves at the observation station $j$ is expressed as,

$$
d_{i j}=\left(L_{i} / V_{R}+b_{i j} / V_{S}-a_{i j} / V_{S}\right)
$$

where $L_{i}$ is the fault length, $a_{i j}$ is the distance between the rupture initiation point and the observation station $j, b_{i j}$ is the distance between the rupture termination point and the observation station, $V_{R}$ is the rupture velocity, and $V_{S}$ is the $S$-wave velocity. For the symmetric bilateral case, the farther end of the fault plane from the station is regarded as the rupture termination point. The method by Izutani and Hirasawa $(1987 \mathrm{a}, \mathrm{b})$ is based on the strong correlation between the strong motion duration, $D_{i j}$, and the apparent duration of rupture propagation, $d_{i j}$.

Making a small modification to the method of Izutani and Hirasawa $(1987 \mathrm{a}, \mathrm{b})$, we assume that $D_{i j}$ is in proportion to $d_{i j}$ as,

$$
D_{2 j} / D_{1 j}=d_{2 j} / d_{1 j},
$$

where the subscripts 1 and 2 stand for the main shock and the largest aftershock, respectively. The fault length, $L_{1}$, and the direction of rupture propagation, $\phi_{1}$, for the main shock are given by source models from previous studies, and $d_{1 j}$ is obtained by Eq. (2). Then, varying $L_{2}$ and $\phi_{2}$, the expected value of strong motion duration, $D_{2 j}^{\mathrm{c}}$, is calculated by Eqs. (2) and (3). A criterion,

$$
\epsilon^{2}=\sum_{j=1}^{4}\left(D_{2 j}^{\mathrm{o}}-D_{2 j}^{\mathrm{c}}\right)^{2} \rightarrow \text { minimum }
$$

is adopted to find the best-fit values for $L_{2}$ and $\phi_{2}$, where $D_{2 j}^{\mathrm{o}}$ indicates the observed strong motion duration.

\section{Fault Plane of the Largest Aftershock}

Many source models have been presented for the main shock (e.g., Kanamori, 1971; Mori and Shimazaki, 1984, 1985; Kikuchi and Fukao, 1985; Schwartz and Ruff, 1985). Although the details of the various fault models are different, the overall rupture process on the fault plane is similar in each case: that is, a unilateral rupture propagation of about $150 \mathrm{~km}$ towards the north. We adopt the source model of Mori and Shimazaki (1984) which was derived from short-period seismic waves. They determined the locations of two subevents which had radiated very strong high-frequency energy as shown in Fig. 1. Although the extent of the aftershock area suggests a bilateral propagation of the fault rupture, they concluded that the main rupture had propagated unilaterally between the two subevents. The location of the first subevent is very close to the epicenter of I-phase determined by Nagamune (1971), which is the epicenter of a very strong phase recorded on seismograms at observation stations operated by the Japan Meteorological Agency (JMA). Also, asperities obtained by Kikuchi and Fukao (1985) are located at almost the same places as the two subevents.

We adopt the origin of I-phase as the initiation point of the main rupture. The depth of the rupture initiation point is 


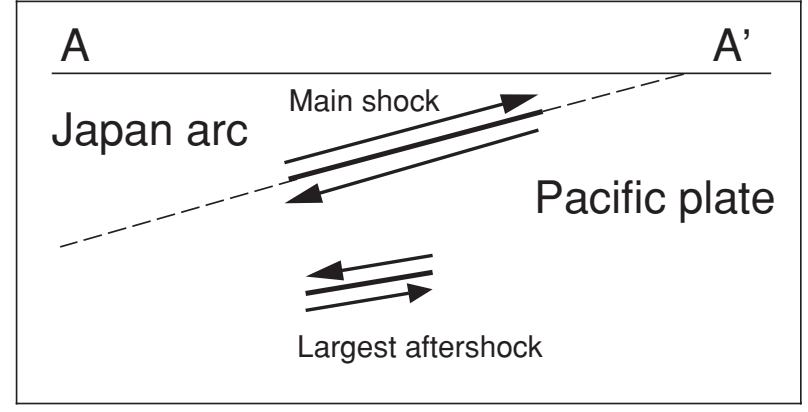

Fig. 5. Schematic illustration of the slip vectors for the main shock and the largest aftershock projected on the vertical section along $\mathrm{A}-\mathrm{A}^{\prime}$ in Fig. 1. The thick solid lines and the arrows indicates the fault planes and the slip vectors. The broken line indicates the boundary between the Pacific plate and the Japan arc.

assumed to be $30 \mathrm{~km}$, by taking into account the focal depth by JMA and the focal mechanism solution by Kanamori (1971). The length and the direction of the rupture propagation are assumed to be the distance and the direction between the two subevents, i.e., $L_{1}=120 \mathrm{~km}$ and $\phi_{1}=10^{\circ}$.

As the rupture initiation point of the largest aftershock, we adopt the hypocenter location determined by JMA. Varying $V_{R} / V_{S}$ from 0.5 to 0.9 , the sum of the squares of residuals, $\epsilon^{2}$ in Eq. (4), is calculated. $\epsilon^{2}$ for the unilateral rupture propagation is shown in Fig. 4 with contour lines in the cases of $V_{R} / V_{S}$ of 0.6 and/or 0.8. Since we are using the ratio between $d_{1 j}$ and $d_{2 j}$, the absolute value of $V_{S}$ does not affect the result. Although a tradeoff can be seen between $V_{R} / V_{S}$ and $L_{2}$, the direction of rupture propagation, $\phi_{2}$, is rather stable and is not affected significantly by the assumption of $V_{R} / V_{S}$. The fault length of the largest aftershock is evaluated as $L_{2}=30 \sim 60 \mathrm{~km}$, and the rupture propagation direction as $\phi_{2}=60 \sim 110^{\circ}$. For the symmetric bilateral rupture propagation, $\epsilon^{2}$ was larger than that for the unilateral case.

We have obtained the above result by assuming that the rupture propagated on the gently-dipping $P$-wave nodal plane. Analyses were also made for rupture propagation on the steeply-dipping $P$-wave nodal plane, and $\epsilon^{2}$ was confirmed to be very large. The fault plane of the largest aftershock is shown schematically in Fig. 1. If we assume that the rupture initiation point is the hypocenter location determined by JMA, the fault plane is located considerably further north of the tsunami source area given by Hatori (1969).

\section{Discussion}

The fault plane of the largest aftershock derived in the present study is located at the northern end of the aftershock area within 24 hours after the main shock. If the fault plane of the largest aftershock is a part of the fault plane of the main shock, the Pacific plate must have moved northwestward during the main shock and southeastward during the largest aftershock. This movement of the Pacific plate seems quite unnatural. Judging from the focal depth and the focal mechanism solution of the main shock, the depth of the fault plane of the main shock is about $20 \mathrm{~km}$ in the epicentral area of the largest aftershock, while the focal depth of the largest aftershock determined by JMA is $40 \mathrm{~km}$. Therefore, the fault planes of the two events would be almost parallel to each other.

The broken line marked with $\mathrm{A}$ and $\mathrm{A}^{\prime}$ in Fig. 1 is approximately parallel to the direction of motion of the Pacific plate against the Japan arc. Figure 5 schematically shows slip vectors during the two events projected onto the vertical section along $\mathrm{A}-\mathrm{A}^{\prime}$. The thrust faulting of the main shock and the normal faulting of the largest aftershock indicate that the part of the Pacific plate between the two fault planes moved relatively further northwestward, due to the two events, than the deeper part beneath the fault plane of the largest aftershock. This result might provide a hint regarding the deformation process of the Pacific plate descending near the junction of the Japan and the Kuril trenches.

Acknowledgments. Accelerogams from Port and Harbour Research Institute, Japan, and the World Data Center A for Solid Earth Geophysics are analyzed in this study. Comments from Tatsuhiko Hara and two anonymous reviewers were very helpful in the revision of the manuscript.

\section{References}

Felzer, K. R. and E. E. Brodsky, Decay of aftershock density with distance indicates triggering by dynamic stress, Nature, 441/8, doi:10.1038/nature04799, 2006.

Hatori, T., Dimensions and geographic distribution of tsunami sources in Japan, Bull. Earthq. Res. Inst., 47, 185-214, 1969.

Izutani, Y. and T. Hirasawa, Use of strong motion duration for rapid evaluation of fault parameters, J. Phys. Earth, 35, 171-190, 1987a.

Izutani, Y. and T. Hirasawa, Rapid estimation of fault parameters for nearfield tsunami warning, Nat. Disas. Sci., 9, 99-113, 1987b.

Kanamori, H., Focal mechanism of the Tokachi-Oki earthquake of May 16, 1968: Contortion of the lithosphere at a junction of two trenches, Tectonophysics, 12, 1-13, 1971.

Kikuchi, M. and Y. Fukao, Iterative deconvolution of complex body waves from great earthquakes - the Tokachi-oki earthquake of 1968, Phys. Earth Planet. Inter., 37, 235-248, 1985.

King, G. C. P., R. S. Stein, and J. Lin, Static stress changes and the triggering of earthquakes, Bull. Seismol. Soc. Am., 84, 935-953, 1994.

Mori, J. and K. Shimazaki, High stress drops of short-period subevents from the 1968 Tokachi-Oki earthquake as observed on strong-motion records, Bull. Seismol. Soc. Am., 74, 1529-1544, 1984.

Mori, J. and K. Shimazaki, Inversion of intermediate-period Rayleigh waves for source characteristics of the 1968 Tokachi-Oki earthquake, J. Geophys. Res., 90, 11,374-11,382, 1985.

Nagamune, T., Source regions of great earthquakes, Geophys. Mag., 35, 333-399, 1971.

Schwartz, S. Y. and L. J. Ruff, The 1968 Tokachi-Oki and the 1969 Kurile islands earthquakes: Variability in the rupture process, J. Geophys. Res., 90, 8613-8626, 1985.

Tsuchida, H., E. Kurata, and K. Sudo, Strong-motion earthquake records on the 1968 Tokachi-Oki earthquake and its aftershocks, Tech. Note Port Harbour Res. Inst., No. 80, 1-476, 1969.

Yamakawa, N., M. Kishio, and I. Maeda, Aftershocks of the TokachiOki earthquakes of 1968 (II)—Spatial and temporal distributions of the aftershocks and the focal mechanisms of the main shock and major aftershocks-, Geophys. Mag., 36, 53-73, 1972.

Y. Izutani (e-mail: tdp0000@shinshu-u.ac.jp) 